\title{
A Facile Synthesis of SAPO-34 Molecular Sieves with Microwave Irradiation in Wide Reaction Conditions
}

\author{
Jong Won Jun, Ji Sun Lee, ${ }^{\dagger}$ Hwi Young Seok, Jong-San Chang, ${ }^{\dagger}$ Jin-Soo Hwang, ${ }^{\dagger}$ and Sung Hwa Jhung ${ }^{*}$ \\ Department of Chemistry and Green-Nano Materials Research Center, Kyungpook National University, Daegu 702-701, Korea \\ *E-mail: sung@knu.ac.kr \\ †Bio-refinerary Research Center, Korea Research Institute of Chemical Technology, P.O. Box, 107, Yusung, \\ Daejeon 305-600, Korea \\ Received March 3, 2011, Accepted April 30, 2011
}

\begin{abstract}
Various reaction conditions including temperature, time and type and concentration of templates have been changed in order to facilely synthesize, especially with microwave (MW) heating, SAPO-34 molecular sieves. SAPO-34 molecular sieve can be synthesized rapidly with microwave irradiation from a gel containing tetraethylammonium hydroxide (TEAOH) as a template. However, other several templating molecules lead to SAPO-5 molecular sieve under microwave irradiation even though SAPO-34 is obtained by conventional electric synthesis from the same reactant gels. Moreover, SAPO-34 can be obtained more easily by increasing the TEAOH or silica concentration or by increasing the reaction temperature. SAPO-34 can be obtained within $5 \mathrm{~min}$ in a selected condition (high temperature of $210{ }^{\circ} \mathrm{C}$ ) with microwave heating, which may lead to a continuous production of the important material. SAPO-34 synthesized by microwave irradiation is homogeneous and small in size and shows acidity and a stable performance in the dehydration of methanol and 2-butanol to olefins, suggesting potential applications in acid catalysis.
\end{abstract}

Key Words : SAPO-34, Microwave-synthesis, CHA molecular sieve, Acid catalysis, TEAOH

\section{Introduction}

Nanoporous materials including zeolites and aluminophosphate (AlPO) molecular sieves ${ }^{1,2}$ are widely used in catalysis and separation, and are still being developed for new applications. ${ }^{3}$ SAPO-34 molecular sieve with CHA structure is one of the molecular sieves containing a small pore (pore size of $0.38 \mathrm{~nm}$ ) composed of 8 -membered rings $(8 \mathrm{MR})^{4}$ and has attracted much interest not only for fundamental understanding but also for applications including catalysis called 'methanol to olefin' (MTO) process ${ }^{5-10}$ and selective adsorption/separation. ${ }^{11}$

So far, nanoporous materials including zeolites and metalorganic frameworks (MOFs, materials composed of not only inorganic clusters but also organic linkers) $)^{12-14}$ have been synthesized mainly by hydrothermal crystallization using conventional electric heating. Recently, nanoporous materials have been synthesized with new methods such as microwave $(\mathrm{MW})^{15,16}$ and ultrasound. ${ }^{17}$ Especially, it has been reported that synthesis of nanoporous materials by microwave heating has many advantages like fast crystallization, ${ }^{15,16}$ facile morphology control ${ }^{18,19}$ and ready evaluation of process parameters. $^{20,21}$ Moreover, the microwave technique has been regarded to lead to small-sized crystals because of high concentration of nuclei and homogeneous heating. ${ }^{22}$ Malinger et al. ${ }^{23,24}$ have shown that octahedral molecular sieve materials (OMS-1, OMS-2) synthesized by microwave methods exhibit superior properties such as stability, crystallinity, morphology and even catalytic activity compared with those of OMS-1 and OMS-2 synthesized by conventional methods.
MW syntheses have also shown phase-selectivity in the syntheses of AlPOs and MOFs. ${ }^{25-28}$ The selective crystallization of a phase has been explained in terms of a kinetic and thermodynamic effect. A less stable AlPO molecular sieve is preferentially obtained with microwaves due to a decreased synthesis time. Similarly, it has also been reported that a less stable MOF (Cr-benzenedicarboxylate called MIL-101) is selectively obtained under microwave heating rather than a more stable MOF (another Cr-benzenedicarboxylate named as MIL-53). ${ }^{28}$

Especially, we have reported that SAPO-5 (AFI structure), rather than SAPO-34 (CHA structure), is mainly synthesized preferentially by microwave heating. ${ }^{25}$ SAPO-5 forms at an early stage of reaction and is transformed into a more stable phase, SAPO-34, with the increase of reaction time. ${ }^{25}$ However, pure SAPO-34 could not be obtained with microwave irradiation, ${ }^{25}$ even in the presence of a SAPO-34 seed, because the selectivity for SAPO-5 is very high or the synthesis time is insufficient with microwave heating (less than $10 \mathrm{~h}$ ).

Even though the microwave synthesis of SAPO-34 has several advantages, to the best of our knowledge, there are only a few reports on the microwave synthesis of SAPO-34 molecular sieves. Very recently, SAPO-34 has been successfully synthesized, under microwave heating, by the transformation of SAPO-5. ${ }^{29}$ However, the precursor gels used were composed of dual templates such as TEAOH and dipropylamine. Moreover, the SAPO-34 is obtained only after $500 \mathrm{~min}$, which is quite long for a microwave synthesis. Recently, van Heyden et al. ${ }^{30}$ reported the synthesis of a nanosized SAPO-34 from clear colloidal precursor solutions. The 
synthesis is a slightly complex process and needs high concentration of phosphoric acid (and accordingly high concentration of the expensive TEAOH template).

Dehydration of an alcohol including MTO process is very important for producing olefins and converting feedstocks into olefinic valuable chemicals. SAPO-34 is one of the most deeply studied catalysts for MTO process. Generally, a small-sized SAPO-34 is superior to large-sized one in catalysis (including the MTO process), ${ }^{5,6}$ especially for steady conversion.

Therefore, it is highly desirable to synthesize a small-sized SAPO-34 with microwave heating especially in the presence of a single template molecule and in a short reaction time. Herein, we report a facile synthesis of SAPO-34 in minutes or a few hours by microwave heating from a reactant gel containing a single template molecule. The effect of reaction conditions like reaction time, reaction temperature and the concentrations of template and silica will be discussed. The synthesized SAPO-34 with microwave has also been applied in the dehydration of methanol and 2-butanol to olefins (MTO) to understand the applicability in an acid catalysis.

\section{Experimental}

SAPO-34 molecular sieves were synthesized from pseudoboehmite (Catapal A, Vista), phosphoric acid (85 wt \%, Aldrich), silica sol (Ludox AS-40, 40\%, Aldrich) and deionized water similar to a reported method. ${ }^{30}$ Tetra-ethylammonium hydroxide (TEAOH, 35\%, Aldrich) was mainly used as a template molecule. Various amines like morpholine, triethanolamine, piperidine and cyclohexylamine (all from Aldrich) were also tried as templating molecules. Silica sol was added dropwise to the aqueous solution of TEAOH and mixed well, and the mixture was aged at $100{ }^{\circ} \mathrm{C}$ for $12 \mathrm{~h}$. Phosphoric acid was added dropwise to pseudoboehmite which was suspended in water. Finally the mixtures of silica and TEAOH were added to the white gel of aluminophosphates. The reactant composition was $\mathrm{Al}_{2} \mathrm{O}_{3}: 1.0 \mathrm{P}_{2} \mathrm{O}_{5}$ : $(0.15-0.45) \mathrm{SiO}_{2}:(1.5-2.5) \mathrm{TEAOH}: 100 \mathrm{H}_{2} \mathrm{O}$, and the typical composition, unless otherwise specified, was $\mathrm{Al}_{2} \mathrm{O}_{3}: 1.0$ $\mathrm{P}_{2} \mathrm{O}_{5}: 0.3 \mathrm{SiO}_{2}: 2,0$ TEAOH : $100 \mathrm{H}_{2} \mathrm{O}$. The reaction conditions for the representative cases are summarized in Table 1.

The gel of $20 \mathrm{~g}$ was loaded in a $100 \mathrm{~mL}$ Teflon autoclave, which was sealed and placed in a microwave oven (Mars-5, CEM, maximum power of $1200 \mathrm{~W}$ ). The autoclave was heated to the reaction temperature of $165-210{ }^{\circ} \mathrm{C}$ in about 2 min and kept for a predetermined time. The microwave power was $300 \mathrm{~W}$ throughout the whole synthesis steps including heating-up stage. The reaction temperature was controlled using the EST-300 Plus system (Electronic Sensor-Temperature) that monitored and controlled temperature conditions inside sample vessels. The detailed synthesis procedure under microwave irradiation is reported elsewhere. ${ }^{31,32}$

For a conventional electric crystallization, the gel (20 g) was loaded in a Teflon lined autoclave and put in a preheated electric oven (the temperature was the same as that of the microwave oven) for a fixed time. During the microwave and conventional reactions, the reactant mixtures were kept without agitation. After the reaction, the autoclave was cooled to room temperature and solid products were recovered by centrifugation and dried overnight at $100{ }^{\circ} \mathrm{C}$. The yield of the solid product was calculated by comparing the amount of recovered solid with the total weight of oxides such as $\mathrm{Al}_{2} \mathrm{O}_{3}, \mathrm{P}_{2} \mathrm{O}_{5}$ and $\mathrm{SiO}_{2}$ in the gel. The contribution of the remained template and water was calibrated with a weight loss at $550{ }^{\circ} \mathrm{C}$ determined with a thermogravimetry system (Du Pont TGA 9900).

The crystal phase of the samples was verified using an Xray diffractometer (MO3X-HF, model no. 1031, CuK $\alpha$ radiation). The morphology and the chemical composition were examined using a scanning electron microscope (Hitachi, S4300) and an energy dispersive X-ray spectrometer (Hitachi, EDX-350), respectively. The nitrogen adsorption isotherms and surface areas were measured at $-196{ }^{\circ} \mathrm{C}$ with a surface area and porosity analyzer (Micromeritics, Tristar II 3020) after evacuation at $300{ }^{\circ} \mathrm{C}$. The surface area was calculated using the BET equation. Before evacuation for adsorption, the SAPO-34 molecular sieves were calcined for $10 \mathrm{~h}$ at 550 ${ }^{\circ} \mathrm{C}$ in air under static condition in order to remove template molecules.

Ammonia-temperature programmed desorption (TPD) pattern was obtained with an Automated Catalyst Characterization System (Micromeritics, AutoChem II 2920) after adsorbing ammonia (15\% ammonia in $\mathrm{He}$, flow rate 50 sccm) at $100{ }^{\circ} \mathrm{C}$ for $1 \mathrm{~h}$ and sweeping for $30 \mathrm{~min}$ at $100{ }^{\circ} \mathrm{C}$ (He $30 \mathrm{sccm})$. The desorption was performed between 100

Table 1. Reaction conditions and results of the synthesis of SAPO- 34 molecular sieves

\begin{tabular}{|c|c|c|c|c|c|}
\hline \multirow{2}{*}{$\begin{array}{l}\text { Sample } \\
\text { No. }\end{array}$} & \multicolumn{2}{|l|}{ Reaction conditions $^{a}$} & \multicolumn{3}{|c|}{ Reaction results } \\
\hline & Molar composition & $\begin{array}{l}\text { Heating } \\
\text { method }^{a}\end{array}$ & Phase & $\begin{array}{c}\text { Composition } \\
(\mathrm{Si} /(\mathrm{Al}+\mathrm{P}+\mathrm{Si}), \text { atom \%) }\end{array}$ & $\mathrm{S}_{\mathrm{BET}}{ }^{c}$ \\
\hline A & $\mathrm{Al}_{2} \mathrm{O}_{3}: 1.0 \mathrm{P}_{2} \mathrm{O}_{5}: 0.15 \mathrm{SiO}_{2}: 2.0$ TEAOH $: 100 \mathrm{H}_{2} \mathrm{O}$ & MW & $\mathrm{CHA}^{b}$ & 6.3 & 564 \\
\hline B & $\mathrm{Al}_{2} \mathrm{O}_{3}: 1.0 \mathrm{P}_{2} \mathrm{O}_{5}: 0.30 \mathrm{SiO}_{2}: 2.0$ TEAOH $: 100 \mathrm{H}_{2} \mathrm{O}$ & MW & CHA & 8.6 & 500 \\
\hline $\mathrm{C}$ & $\mathrm{Al}_{2} \mathrm{O}_{3}: 1.0 \mathrm{P}_{2} \mathrm{O}_{5}: 0.45 \mathrm{SiO}_{2}: 2.0$ TEAOH $: 100 \mathrm{H}_{2} \mathrm{O}$ & MW & CHA & 12.4 & 538 \\
\hline $\mathrm{D}$ & $\mathrm{Al}_{2} \mathrm{O}_{3}: 1.0 \mathrm{P}_{2} \mathrm{O}_{5}: 0.15 \mathrm{SiO}_{2}: 2.0$ TEAOH $: 100 \mathrm{H}_{2} \mathrm{O}$ & $\mathrm{CE}$ & CHA & 5.8 & 530 \\
\hline $\mathrm{E}$ & $\mathrm{Al}_{2} \mathrm{O}_{3}: 1.0 \mathrm{P}_{2} \mathrm{O}_{5}: 0.30 \mathrm{SiO}_{2}: 2.0$ TEAOH $: 100 \mathrm{H}_{2} \mathrm{O}$ & $\mathrm{CE}$ & $\mathrm{CHA}$ & 7.9 & 459 \\
\hline $\mathrm{F}$ & $\mathrm{Al}_{2} \mathrm{O}_{3}: 1.0 \mathrm{P}_{2} \mathrm{O}_{5}: 0.45 \mathrm{SiO}_{2}: 2.0$ TEAOH $: 100 \mathrm{H}_{2} \mathrm{O}$ & $\mathrm{CE}$ & CHA & 11.5 & 494 \\
\hline
\end{tabular}

${ }^{a} \mathrm{MW}$ : microwave heating for $2 \mathrm{~h}$; CE: conventional electric heating for $2 \mathrm{~d}$; reaction temperature: $190{ }^{\circ} \mathrm{C} .{ }^{b} \mathrm{Contaminated}$ with small amount of SAPO-5. ${ }^{c}$ BET surface area $\left(\mathrm{m}^{2} / \mathrm{g}\right)$ 
and $600{ }^{\circ} \mathrm{C}$ with the ramping rate of $10{ }^{\circ} \mathrm{C} / \mathrm{min}$ under $\mathrm{He}$ flow $(30 \mathrm{sccm})$. Before adsorption, the SAPO-34s were pretreated with He flowing $(50 \mathrm{sccm})$ under heating. The temperature was increased from 30 to $500{ }^{\circ} \mathrm{C}$ with the heating rate of $10{ }^{\circ} \mathrm{C} / \mathrm{min}$ and maintained for $3 \mathrm{~h}$ at $500{ }^{\circ} \mathrm{C}$ ).

The dehydration of alcohols to olefins was carried out at atmospheric pressure with a conventional fixed-bed reactor made of a stainless steel tube. The alcohols were fed with a syringe pump and nitrogen $(30 \mathrm{cc} / \mathrm{min})$ was used as a carrier gas. The SAPO-34 calcined at $550{ }^{\circ} \mathrm{C}$ was dehydrated at 450 ${ }^{\circ} \mathrm{C}$ for $2 \mathrm{~h}$ before reaction. The WHSV was 2 and $1 \mathrm{~h}^{-1}$, respectively, for methanol and 2-butanol, and the weight of SAPO-34 was $0.2 \mathrm{~g}$. The products and fed alcohols were analyzed with an on-lined GC equipped with a FID detector.

\section{Results}

Before synthesis of SAPO-34 with the microwave technique from the gel containing $\mathrm{TEAOH}$, the synthesis was carried out with gels composed of various templates (like morpholine, triethanolamine, piperidine and cyclohexylamine) that have been used for the conventional synthesis of CHA-type molecular sieves. ${ }^{5,33-35}$ However, as shown in
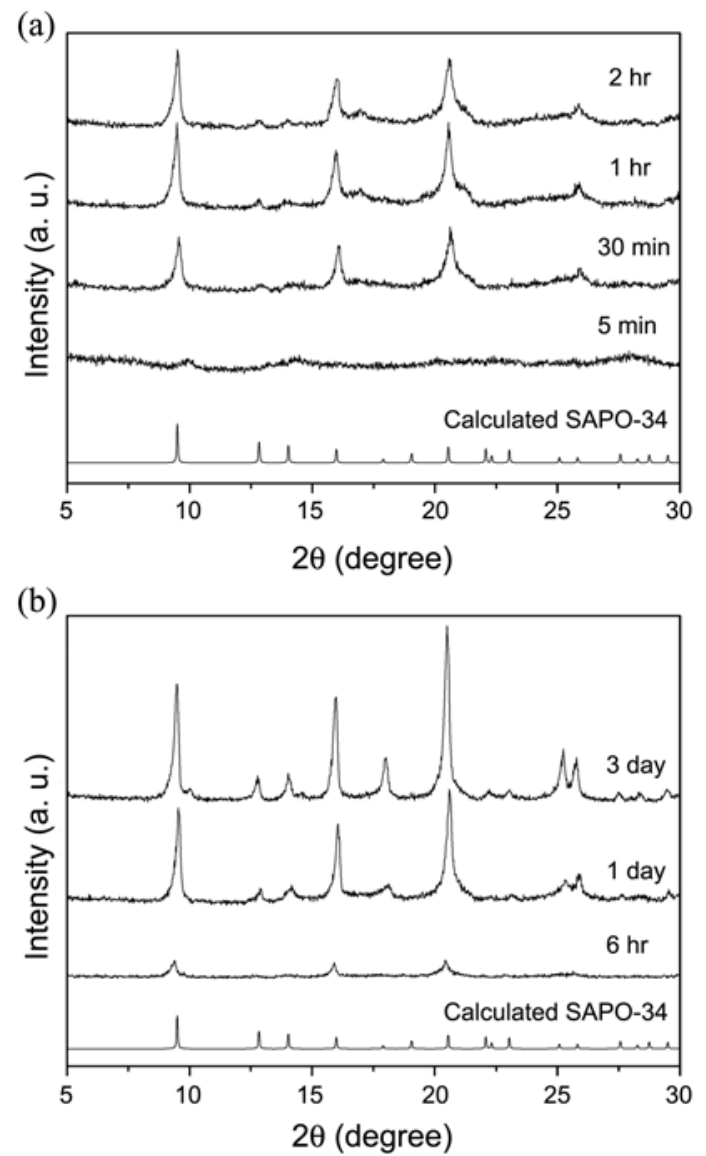

Figure 1. Effect of synthesis time on the XRD patterns of SAPO molecular sieves synthesized with (a) MW heating and (b) conventional electric heating at $190{ }^{\circ} \mathrm{C}$. The molar composition of the reaction mixture was $\mathrm{Al}_{2} \mathrm{O}_{3}: 1.0 \mathrm{P}_{2} \mathrm{O}_{5}: 0.30 \mathrm{SiO}_{2}: 2.0 \mathrm{TEAOH}$ : $100 \mathrm{H}_{2} \mathrm{O}$. Calculated XRD pattern of SAPO-34 is also shown for comparison.
Supporting Figure 1, the main product from the gels $\left(\mathrm{Al}_{2} \mathrm{O}_{3}\right.$ : $1.0 \mathrm{P}_{2} \mathrm{O}_{5}: 0.30 \mathrm{SiO}_{2}: 2.0$ template $: 100 \mathrm{H}_{2} \mathrm{O}$ ) was SAPO-5 or a mixture of SAPO-5 and SAPO-34 after synthesis in even severe condition of long reaction time $\left(4 \mathrm{~h}\right.$ at $\left.200{ }^{\circ} \mathrm{C}\right)$. Changes in reaction conditions like concentration, temperature and time do not lead to pure SAPO-34 under microwave irradiation.

Figure 1 presents the XRD patterns of the molecular sieves synthesized from gels containing TEAOH (reactant composition is $\mathrm{Al}_{2} \mathrm{O}_{3}: 1.0 \mathrm{P}_{2} \mathrm{O}_{5}: 0.30 \mathrm{SiO}_{2}: 2.0 \mathrm{TEAOH}$ : $100 \mathrm{H}_{2} \mathrm{O}$ ) for various reaction times by both microwave and conventional electric heating. The XRD patterns match with the calculated pattern of SAPO-34 especially when the reaction time is longer than $30 \mathrm{~min}$ (by MW heating) and $1 \mathrm{~d}$ (by CE heating), showing the successful synthesis of SAPO34 with both MW and CE syntheses in the selected condition. The SAPO-34 may be contaminated with dense impurities such as tridymite, cristobalite and quartz because XRD pattern has a shoulder at 2 theta of 21-22. However, the content of impurities may be low considering the surface area of SAPO-34 (see below) and high XRD intensity of the dense phases. Compared with the results of Supporting Figure 1, the results of Figure 1 show the beneficial role of TEAOH in the microwave-synthesis of SAPO-34. Figure 2 shows the changes in the yields of SAPO-34 with the synthesis time for the MW and CE syntheses. The yields increase steadily with reaction time and the synthesis is nearly completed in $3 \mathrm{~h}$ and $3 \mathrm{~d}$ with MW and CE synthesis, respectively, at $190{ }^{\circ} \mathrm{C}$. The reaction time can be decreased further with increasing the reaction temperature (see below).

The effect of concentration of the template (TEAOH) was evaluated and Figure 3 shows the XRD patterns of the obtained products from gels with various TEAOH concentrations $\left(\mathrm{Al}_{2} \mathrm{O}_{3}: 1.0 \mathrm{P}_{2} \mathrm{O}_{5}: 0.30 \mathrm{SiO}_{2}:(1.5-2.5) \mathrm{TEAOH}\right.$ : $100 \mathrm{H}_{2} \mathrm{O}$ ) after $2 \mathrm{~h}$ at $190{ }^{\circ} \mathrm{C}$. If the TEAOH concentration is low (TEAOH $/ \mathrm{Al}_{2} \mathrm{O}_{3}$ is 1.5) not only SAPO-34 but also SAPO-5 are observed in accordance with the fact that

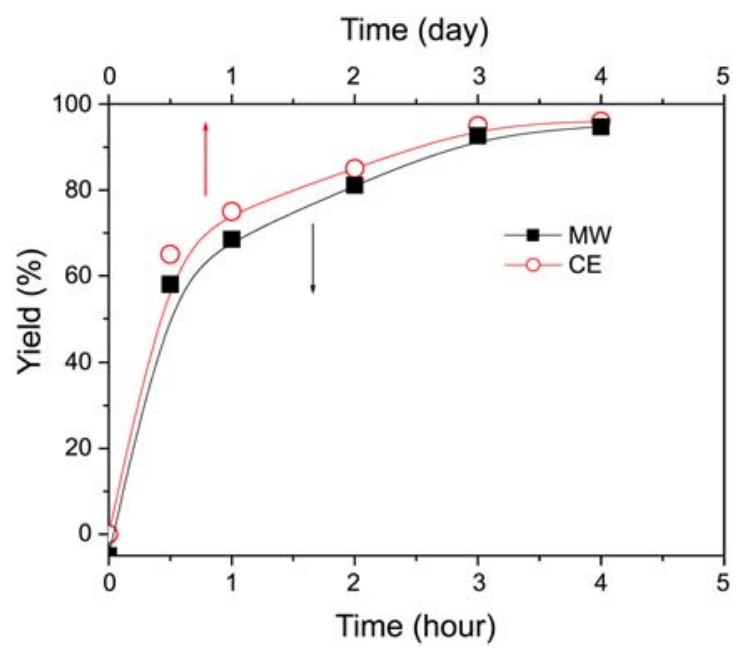

Figure 2. Effect of synthesis time on the yields of SAPO molecular sieves synthesized with MW heating and conventional electric heating at $190{ }^{\circ} \mathrm{C}$. The molar composition of the reaction mixture was $\mathrm{Al}_{2} \mathrm{O}_{3}: 1.0 \mathrm{P}_{2} \mathrm{O}_{5}: 0.30 \mathrm{SiO}_{2}: 2.0 \mathrm{TEAOH}: 100 \mathrm{H}_{2} \mathrm{O}$. 

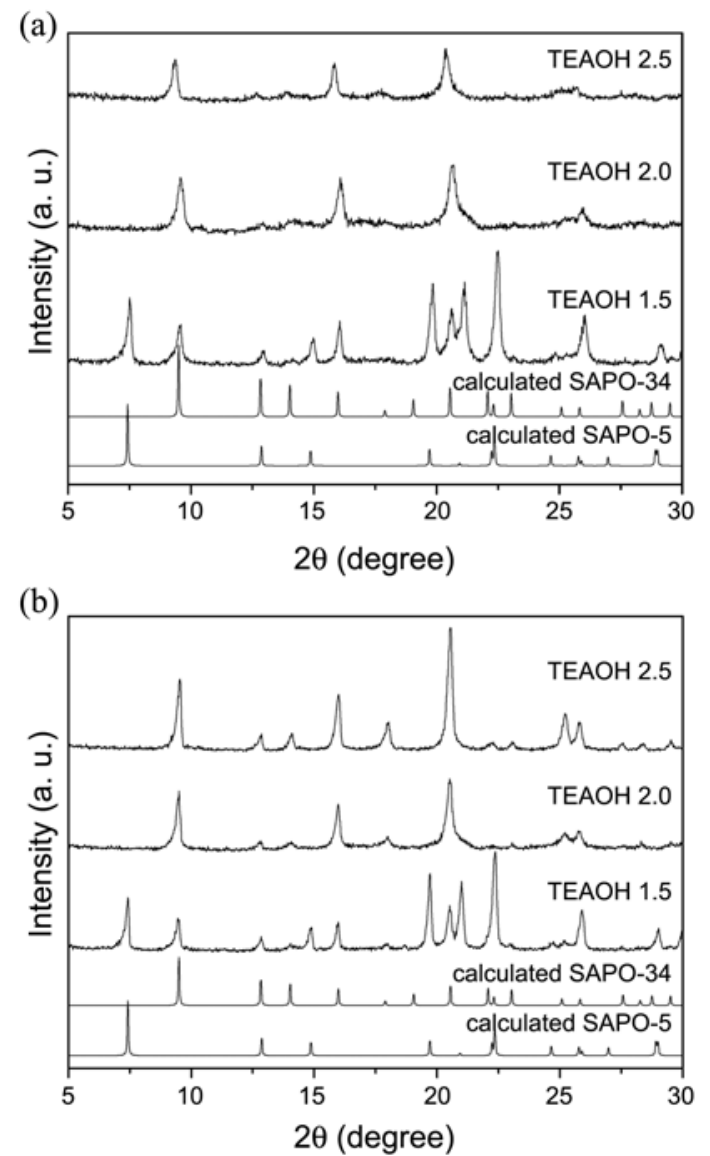

Figure 3. Effect of TEAOH concentrations on the XRD patterns of SAPO molecular sieves synthesized with (a) MW heating and (b) conventional electric heating at $190{ }^{\circ} \mathrm{C}$. The molar composition of the reaction mixture was $\mathrm{Al}_{2} \mathrm{O}_{3}: 1.0 \mathrm{P}_{2} \mathrm{O}_{5}: 0.30 \mathrm{SiO}_{2}:(1.5-2.5)$ TEAOH : $100 \mathrm{H}_{2} \mathrm{O}$. Calculated XRD patterns of SAPO-5 and SAPO-34 are also shown for comparison.

SAPO-5, compared with SAPO-34, is preferentially obtained at high acidic condition. ${ }^{36,37}$

Figure 4 shows the effect of reaction temperature on the synthesis from the gel having the composition of $\mathrm{Al}_{2} \mathrm{O}_{3}: 1.0$ $\mathrm{P}_{2} \mathrm{O}_{5}: 0.30 \mathrm{SiO}_{2}: 2.0$ TEAOH $: 100 \mathrm{H}_{2} \mathrm{O}$. SAPO-34 is the sole product from CE synthesis at any temperature (165-200 ${ }^{\circ} \mathrm{C}$ ). Similarly, SAPO-34 is obtained selectively with microwave heating at a temperature of $170{ }^{\circ} \mathrm{C}$ or higher. However, SAPO-5 is the main product from the microwave heating at $165{ }^{\circ} \mathrm{C}$, showing the preferential synthesis of SAPO-5 at lower temperatures, especially under microwave heating.

The synthesis of SAPO-34 has been tried in various silica contents $\left(\mathrm{Al}_{2} \mathrm{O}_{3}: 1.0 \mathrm{P}_{2} \mathrm{O}_{5}:(0.15-0.45) \mathrm{SiO}_{2}: 2.0\right.$ TEAOH: $100 \mathrm{H}_{2} \mathrm{O}$ ). As illustrated in Figure 5, SAPO-34 is the product of both MW and $\mathrm{CE}$ syntheses even though the product synthesized with microwave heating from the gel with the lowest silica content $\left(\mathrm{Al}_{2} \mathrm{O}_{3}: 1.0 \mathrm{P}_{2} \mathrm{O}_{5}: 0.15 \mathrm{SiO}_{2}: 2.0\right.$ TEAOH : $100 \mathrm{H}_{2} \mathrm{O}$ ) has a tint of SAPO-5. Therefore, it may be supposed that SAPO-5 can be selectively formed with decreasing silica content in the reactant gels.

The synthesized SAPO-34s have been analyzed in porosity, composition and morphology. As shown in Figure 6, the

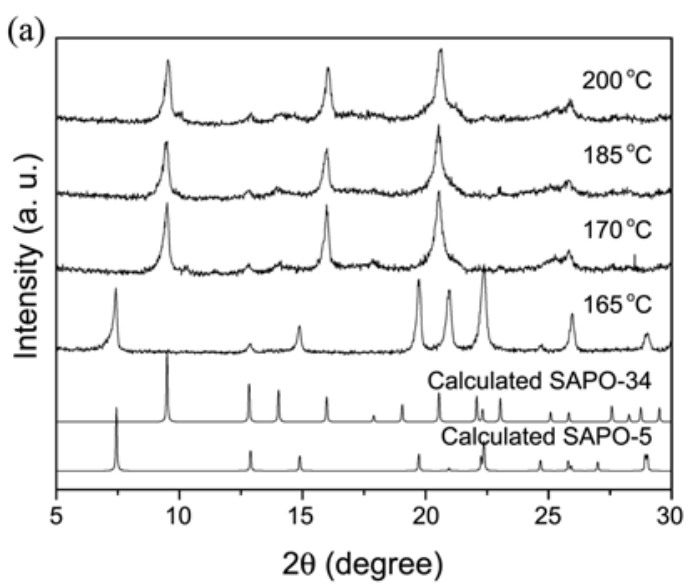

(b)

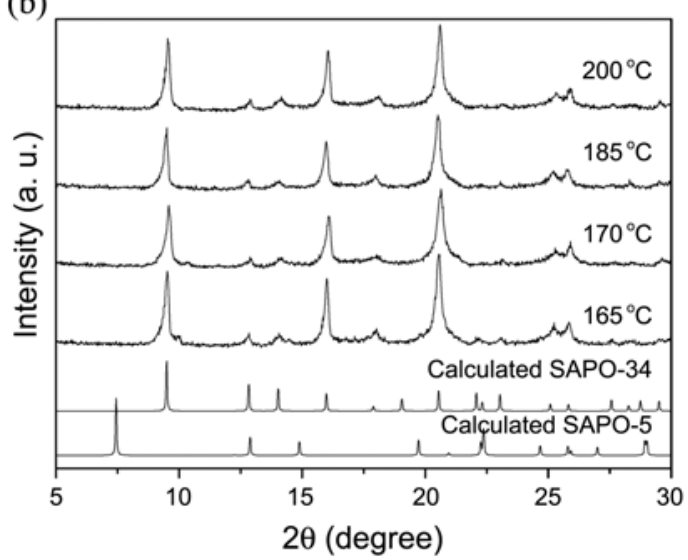

Figure 4. Effect of synthesis temperature on the XRD patterns of SAPO molecular sieves synthesized with (a) MW heating for $2 \mathrm{~h}$ and (b) conventional electric heating for $2 \mathrm{~d}$. The molar composition of the reaction mixture was $\mathrm{Al}_{2} \mathrm{O}_{3}: 1.0 \mathrm{P}_{2} \mathrm{O}_{5}: 0.30 \mathrm{SiO}_{2}$ : 2.0TEAOH : $100 \mathrm{H}_{2} \mathrm{O}$. Calculated XRD patterns of SAPO-5 and SAPO-34 are also shown for comparison.

nitrogen adsorption isotherms of typical SAPO-34s have the traditional type-I isotherms, confirming the microporosity of the SAPO-34 samples. The surface areas (Table 1) of the samples are $460-560 \mathrm{~m}^{2} / \mathrm{g}$, showing the porosity of the obtained samples. The porosity of SAPO-34 samples obtained by MW is similar to those synthesized by electrical heating. The contents of silicon (Table 1) in SAPO-34 increase with increasing the silica concentration in the precursor gels and the contents do not depend much on the synthesis methods of MW and CE heating. The SEM images (Fig. 7) of typical SAPO-34s illustrates that the size is quite small when SAPO-34 is obtained especially with MW heating $(<0.2 \mu \mathrm{m})$. However, the particle size distribution is wide and the size is a bit large when the SAPO-34 is obtained with CE synthesis $(0.2-0.4 \mu \mathrm{m})$.

The rapid synthesis of a molecular sieve is very important not only for commercial applications (like especially for a continuous synthesis of a material) but also for fundamental understanding. The syntheses were carried out at an increased temperature of $210{ }^{\circ} \mathrm{C}$, and the XRD patterns of the SAPO-34s that were synthesized in 3 and 5 min (Fig. 8) show that the SAPO-34 can be crystallized in 3-5 min. The 


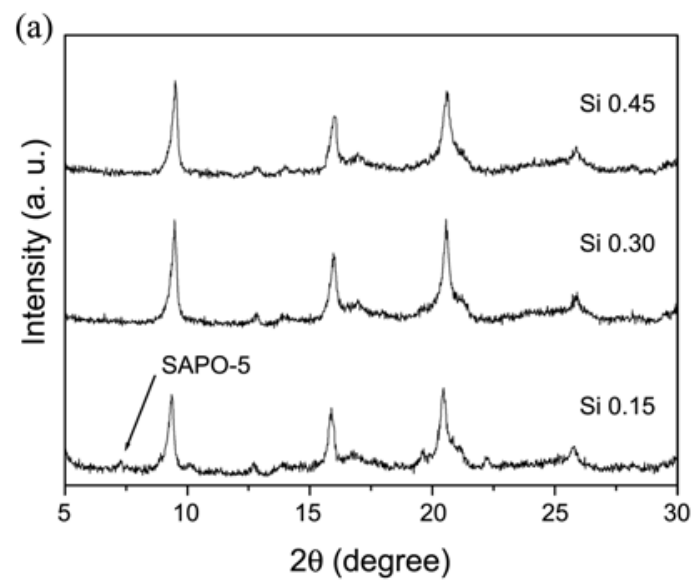

(b)

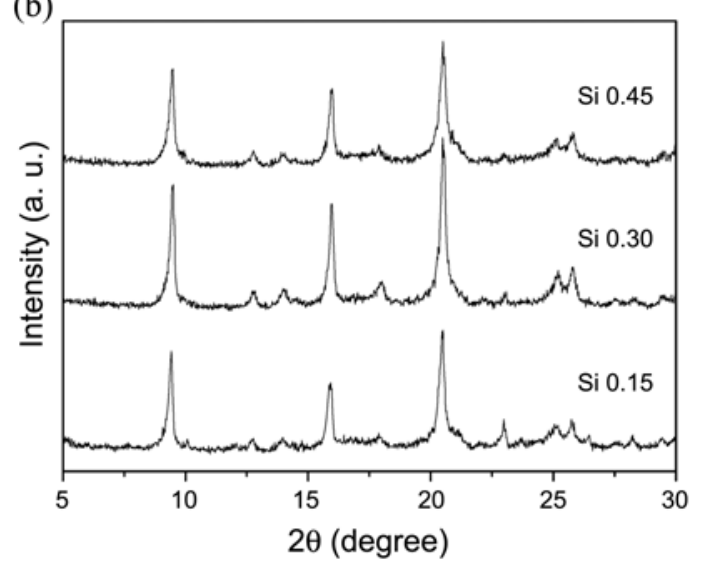

Figure 5. Effect of silica concentration on the XRD patterns of SAPO molecular sieves synthesized with (a) MW heating for $2 \mathrm{~h}$ and (b) conventional electric heating for $2 \mathrm{~d}$ at $190{ }^{\circ} \mathrm{C}$. The molar composition of the reaction mixture was $\mathrm{Al}_{2} \mathrm{O}_{3}: 1.0 \mathrm{P}_{2} \mathrm{O}_{5}:(0.15-$ $0.45) \mathrm{SiO}_{2}: 2.0 \mathrm{TEAOH}: 100 \mathrm{H}_{2} \mathrm{O}$.

yields of the syntheses in the short time are also relatively high (yield $=49 \%$ at $3 \mathrm{~min}, 60 \%$ at $5 \mathrm{~min}$ ). The synthesis of a material in a few minutes may lead to a continuous production of the material, which is very helpful for the commercial production at low cost. ${ }^{31}$

The SAPO-34s synthesized with MW (Sample B) and CE (Sample E) have weak and strong acidity as confirmed with the $\mathrm{NH}_{3}$-TPD pattern (Supporting Fig. 2). The desorption pattern does not depend much on the synthesis method and the pattern is similar to a result reported earlier. ${ }^{7}$ The desorptions of ammonia at $\sim 180$ and $\sim 380{ }^{\circ} \mathrm{C}$ correspond to weak and strong acid sites, ${ }^{7}$ respectively, and suggests the potential applications of the SAPO-34s in acid catalysis. The SAPO34 molecular sieves (Samples B and E) have also been used in the dehydration of methanol and 2-butanol. As shown in Figures 9 and 10, the conversions of olefins were very stable for $2.5 \mathrm{~h}$, which may be due to a small size of the SAPO34. ${ }^{5,6}$ Moreover, the synthesis methods do not show noticeable effect on the product selectivity (Figures 9 and 10).

\section{Discussion}

SAPO-34 molecular sieves have been synthesized in wide
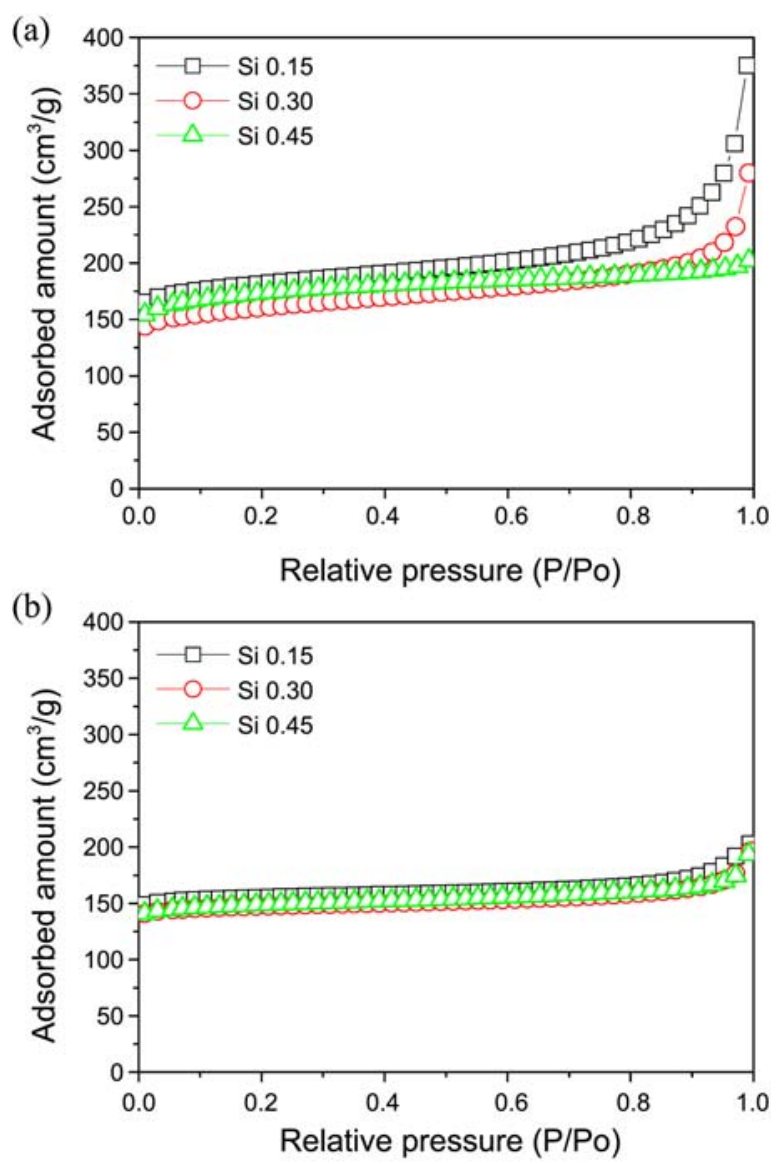

Figure 6. Nitrogen adsorption isotherms of SAPO-34 molecular sieves synthesized with (a) MW heating and (b) conventional electric heating at $190{ }^{\circ} \mathrm{C}$ from different silica concentrations. The molar composition of the reaction mixture was $\mathrm{Al}_{2} \mathrm{O}_{3}: 1.0 \mathrm{P}_{2} \mathrm{O}_{5}$ : (0.15-0.45) $\mathrm{SiO}_{2}: 2.0 \mathrm{TEAOH}: 100 \mathrm{H}_{2} \mathrm{O}$.

reaction conditions because they are very important for catalysis due to a small pore size originated from 8MR. However, microwave syntheses of SAPO-34 have been hardly known even though microwave synthesis has several advantages such as fast crystallization and the formation of small crystals. Only recently the SAPO- 34 has been synthesized in a complex way (like dual templates) with a high template concentration $^{30}$ in colloidal precursor solution or over long periods of time. ${ }^{29}$ In this work, a facile synthesis of SAPO34 with microwave heating has been studied.

Different to other templating molecules, only TEAOH leads to SAPO-34 under microwave heating. Moreover, SAPO-34, rather than SAPO-5, can be obtained selectively when the TEAOH and silica concentrations and the reaction temperature are high. The preferential formation of CHA molecular sieves, rather than AFI molecular sieves, has been observed in the presence of high concentration of heteroatoms like $\mathrm{Mg}^{36}$ and $\mathrm{Co}^{38}$ Moreover, high $\mathrm{pH}$ also leads to CHA molecular sieves. ${ }^{36,37}$ Because of a low stability of AFI (compared with CHA structure) in thermodynamics, due to large pore size ${ }^{26,27}$ or low framework density, ${ }^{39} \mathrm{AFI}$, rather than CHA, is selectively obtained in low temperatures and over shorter reaction times. If the temperature or time 

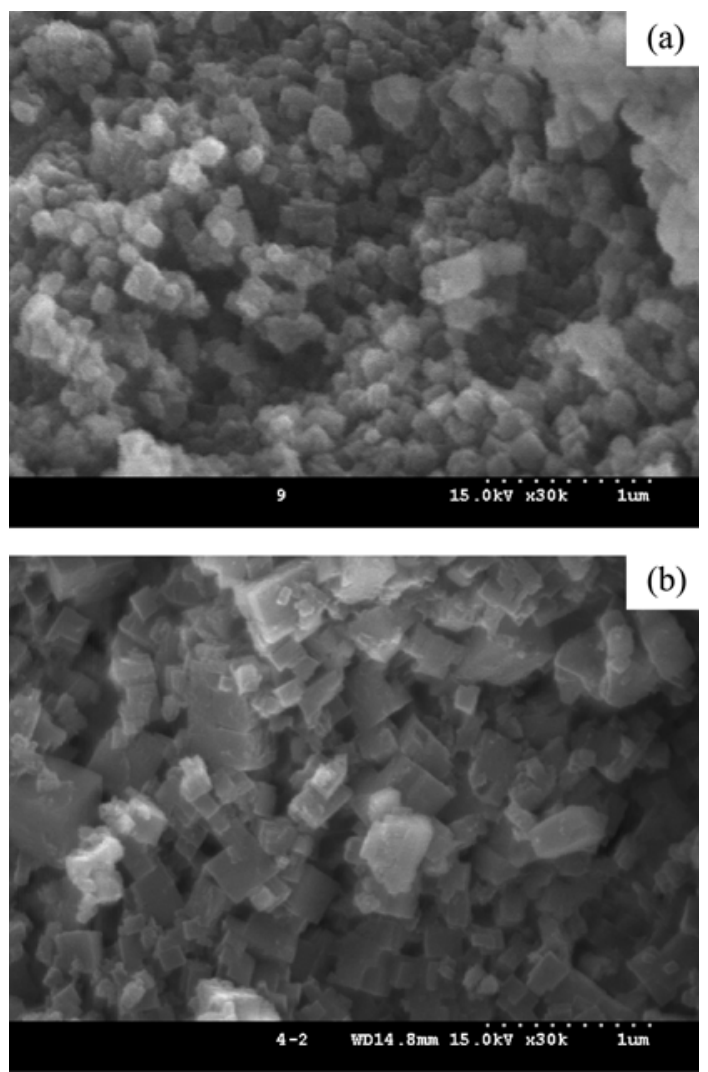

Figure 7. SEM images of SAPO molecular sieves synthesized with (a) MW heating (Sample B) and (b) conventional electric heating (Sample E).

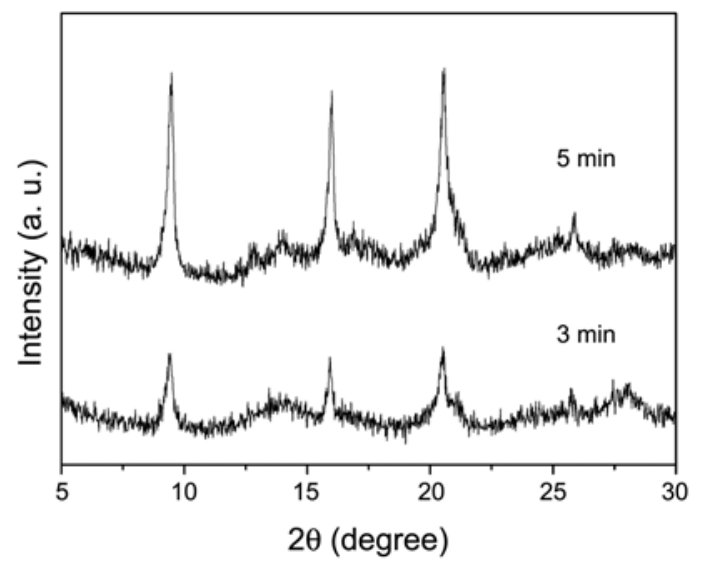

Figure 8. XRD patterns of SAPO molecular sieves synthesized at $210{ }^{\circ} \mathrm{C}$ with $\mathrm{MW}$ heating for $3 \mathrm{~min}$ and $5 \mathrm{~min}$. The molar composition of the reaction mixture was $\mathrm{Al}_{2} \mathrm{O}_{3}: 1.0 \mathrm{P}_{2} \mathrm{O}_{5}: 0.30$ $\mathrm{SiO}_{2}: 2.0 \mathrm{TEAOH}: 100 \mathrm{H}_{2} \mathrm{O}$.

increases, the AFI is replaced with more stable CHA molecular sieves $^{25}$; therefore, severe conditions are helpful to get the CHA structure selectively.

In this study, SAPO-34 is selectively obtained with microwave heating in a restricted condition (high TEAOH and silica contents; high temperature). Most interestingly, SAPO34 can be obtained from a gel containing only TEAOH rather than other amines even though those amines lead to CHA molecular sieve under CE synthesis. ${ }^{5,33-35}$ The reason (a)

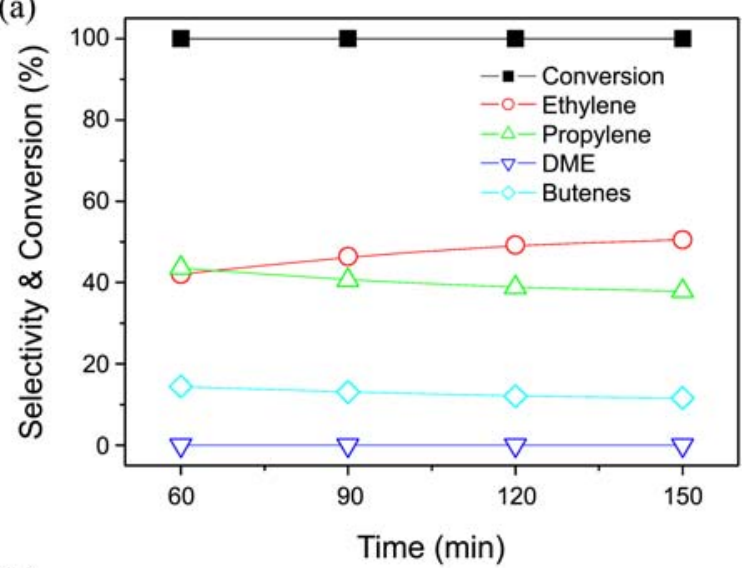

(b)

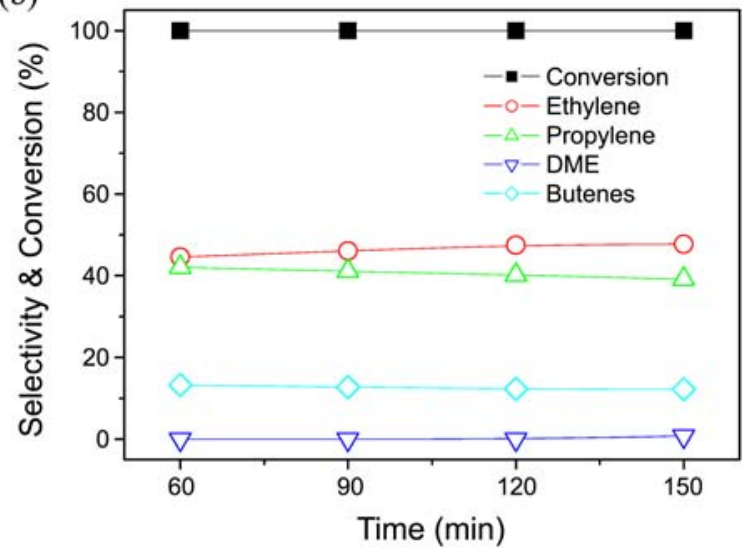

Figure 9. Conversion of methanol and selectivities of olefins and dimethylether (DME) over SAPO-34 molecular sieves ((a): Sample B; (b): Sample E). The reaction temperature was $450{ }^{\circ} \mathrm{C}$.

of the formation of SAPO-34 with only TEAOH under microwave heating is not easy to understand at this moment. Changing other factors such as $\mathrm{pH}$, temperature and silica concentration, even though very important for the synthesis of SAPO-34 under CE heating, ${ }^{36-38}$ does not lead to the formation of the SAPO-34 phase. For example, even a condition of high basicity ( $\mathrm{pH}$ of 9.7 ) and/or seeding of SAPO-34 crystals were not sufficient to produce a pure SAPO-34 molecular sieve when triethylamine was used as the templating molecule. ${ }^{25}$ Therefore, it may be presumed that the TEAOH, especially when the concentration is high, matches well with the SAPO-34 structure or nucleates SAPO34 easily for rapid synthesis under microwave heating. However, further work will be necessary to understand the beneficial role of TEAOH in the selective synthesis of SAPO34 under microwave irradiation. The SAPO-34 can also be obtained in $5 \mathrm{~min}$ at high temperature of $210^{\circ} \mathrm{C}$, which is beneficial for a continuous production of the material with low cost.

The dehydration of methanol over SAPO-34s synthesized with both microwave and conventional heating was highly stable to show practical conversion up to $2.5 \mathrm{~h}$ of time-onstream. Similarly, the conversion of 2-butanol over the two SAPO-34s was also very stable. The stable conversion over the SAPO-34s probably is due to a small size $\mathrm{s}^{22}$ of the SAPO- 
(a)

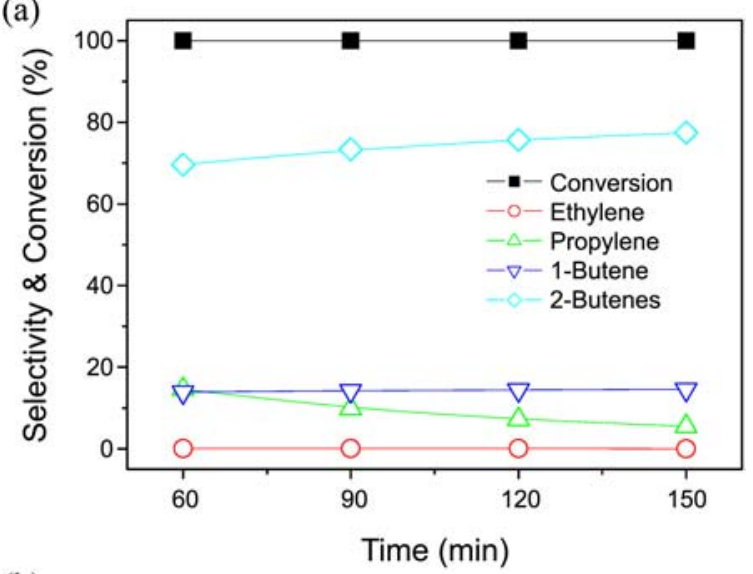

(b)

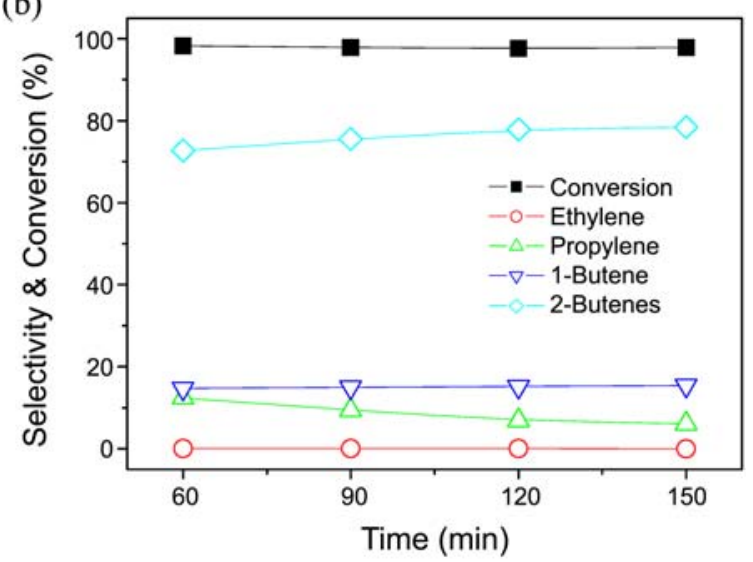

Figure 10. Conversion of 2-butanol and selectivities of olefins over SAPO-34 molecular sieves ((a): Sample B; (b): Sample E). The reaction temperature was $250{ }^{\circ} \mathrm{C}$.

$34 \mathrm{~s}$ obtained in this study. The product selectivities from two dehydrations do not depend much on the synthesis methods (Figs. 9 and 10). The similar performance of the two SAPO$34 \mathrm{~s}$ suggests that the $\mathrm{SAPO}-34$ synthesized with microwave heating has similar characteristics to those of SAPO-34 obtained with conventional synthesis in acidity and catalysis. It can be suggested that the SAPO-34 synthesized with microwave heating can be used in potential applications in an acidic catalysis, which will be accomplished in a next study, based on the acidity confirmed with ammonia TPD and stable performance in the dehydration reactions.

\section{Conclusion}

SAPO-34 molecular sieve can be synthesized facilely from a reactant gel containing TEAOH as a template by utilizing the microwave irradiation technique. However, other templates lead to SAPO-5 under microwave heating even though SAPO-34 is obtained with the templates by conventional electric heating. SAPO-34 can be synthesized more selectively as the concentration of TEAOH or silica increases. The high temperature is also beneficial for the SAPO-34 formation, and the SAPO-34 can be obtained within $5 \mathrm{~min}$ at $210^{\circ} \mathrm{C}$, suggesting a possibility of a continuous production of the valuable material. The SAPO-34s synthesized with microwave irradiation are more homogeneous in morphology and smaller in size than the ones synthesized by conventional electric heating. Finally, it can be suggested that the microwave-synthesized SAPO-34 has the potential applications in heterogeneous acid catalysis because of the very stable conversion of alcohols dehydration and acidity that was confirmed with TPD.

Acknowledgments. This study was supported by a grant (B551179-10-03-00) from the cooperative R\&D Program funded by the Korea Research Council Industrial Science and Technology, Republic of Korea.

\section{References}

1. Wilson, S. T.; Lok, B. M.; Messina, C. A.; Cannan, T. R.; Flanigen, E. M. J. Am. Chem. Soc. 1982, 104, 1146-1147.

2. Wilson, S. T. Stud. Surf. Sci. Catal. 2001, 137, 229-260.

3. Davis, M. E. Nature 2002, 417, 813-821.

4. The crystal structures, framework densities and related materials of all AlPOs studied in this article can be retrieved in the web site of International Zeolite Association (http://www.iza-structure.org/ databases/).

5. Nishiyama, N.; Kawaguchi, M.; Hirota, Y.; Van Vu, D.; Egashira, Y.; Ueyama, K. Appl. Catal. A: General 2009, 362, 193-199.

6. Lee, K. Y.; Chae, H.-J.; Jeong, S.-Y.; Seo, G. Appl. Catal. A: General 2009, 369, 60-66.

7. Lee, Y.-J.; Baek, S.-C.; Jun, K.-W. Appl. Catal. A: General 2007, 329, 130-136.

8. Wragg, D. S.; Johnsen, R. E.; Balasundaram, M.; Norby, P.; Fjellvåg, H.; Grønvold, A.; Fuglerud, T.; Hafizovic, J.; Vistad, Ø. B.; Akporiaye, D. J. Catal. 2009, 268, 290-296.

9. Izadbakhsh, A.; Farhadi, F.; Khorasheh, F.; Sahebdelfar, S.; Asadi, M.; Feng, Y. Z. Appl. Catal. A: General 2009, 364, 48-56.

10. Hereijgers, B. P. C.; Bleken, F.; Nilsen, M. H.; Svelle, S.; Lillerud, K.-P.; Bjørgen, M.; Weckhuysen, B. M.; Olsbye, U. J. Catal. 2009, 264, 77-87.

11. Tian, Y.; Fan, L.; Wang, Z.; Qiu, S.; Zhu, G. J. Mater. Chem. 2009, 19, 7698-7703.

12. Férey, G. future, Chem. Soc. Rev. 2008, 37, 191-214.

13. Kitagawa, S.; Kitaura, R.; Noro, S.-I. Angew. Chem. Int. Ed. 2004, 43, 2334-2375.

14. Yaghi, O. M.; O'Keeffe, M.; Ockwig, N. W.; Chae, H. K.; Eddaoudi, M.; Kim, J. Nature 2003, 423, 705-714.

15. Park, S.-E.; Chang, J.-S.; Hwang, Y. K.; Kim, D. S.; Jhung, S. H.; Hwang, J. S. Catal. Survey Asia 2004, 8, 91-110.

16. Tompsett, G. A.; Conner, W. C.; Yngvesson, K. S. ChemPhysChem. 2006, 7, 296-319.

17. Haque, E.; Khan, N. A.; Park, J. H.; Jhung, S. H. Chem. Eur. J. 2010, 16, 1046-1052.

18. Hwang, Y. K.; Chang, J.-S.; Park, S.-E.; Kim, D. S.; Kwon, Y. U. ; Jhung, S. H.; Hwang, J.-S.; Park, M. S. Angew. Chem. Int. Ed. 2005, 44, 557-560.

19. Jhung, S. H.; Yoon, J. W.; Hwang, Y. K.; Chang, J.-S. Microporous Mesoporous Mater. 2006, 89, 9-15.

20. Jhung, S. H.; Chang, J.-S.; Hwang, Y. K.; Park, S.-E. J. Mater. Chem. 2004, 14, 280-285.

21. Jhung, S. H.; Chang, J.-S.; Yoon, J. W.; Grenèche, J.-M.; Férey, G.; Cheetham, A. K. Chem. Mater. 2004, 16, 5552-5555.

22. Jhung, S. H.; Jin, T.; Hwang, Y.-K.; Chang, J.-S. Chem. Eur. J. 2007, 13, 4410-4417.

23. Malinger, K. A.; Laubernds, K.; Son, Y.-C.; Suib, S. L. Chem. Mater. 2004, 16, 4296-4303.

24. Malinger, K. A.; Ding, Y.-S.; Sithambaram, S.; Espinal, L.; Gomez, S.; Suib, S. L. J. Catal. 2006, 239, 290-298. 
25. Jhung, S. H.; Chang, J.-S.; Hwang, J. S.; Park, S.-E. Microporous Mesoporous Mater. 2003, 64, 33-39.

26. Jhung, S. H.; Jin, T.; Kim, Y. H.; Chang, J.-S. Microporous Mesoporous Mater. 2008, 109, 58-65.

27. Jhung, S. H.; Jin, T.; Hwang, J.-S.; Chang, J.-S. J. Nanosci. Nanotech. 2008, 7, 2734-2740.

28. Khan, N. A.; Jhung, S. H. Cryst. Growth Des. 2010, 10, 18601865.

29. Venna S. R.; Carreon, M. A. J. Mater. Chem. 2009, 19, 31383140.

30. van Heyden, H.; Mintova, S.; Bein, T. Chem. Mater. 2008, 20, 2956-2963.

31. Jhung, S. H.; Yoon, J. W.; Hwang, J.-S.; Cheetham, A. K.; Chang, J.-S. Chem. Mater. 2005, 17, 4455-4460.

32. Jhung, S. H.; Chang, J.-S.; Hwang, Y. K.; Grenèche, J.-M.; Férey, G.; Cheetham, A. K. J. Phys. Chem. B 2005, 109, 845-850.
33. Schott-Darie, C.; Kessler, H.; Benazzi, E. Stud. Surf. Sci. Catal. 1994, 83, 3-10.

34. González, G.; Piña, C.; Jacas, A.; Hernández, M.; Leyva, A. Microporous Mesoporous Mater. 1998, 25, 103-108.

35. Batista, J.; Kauèiè, V.; Rajiæ, N.; Stojakoviæ, D. Zeolites 1992 , $12,925-928$.

36. Concepción, P.; Nieto, J. M. L.; Mifsud, A.; Pérez-Pariente, J. Zeolites 1996, 16, 56-64.

37. Xu, Y.; Maddox, J.; Couves, J. W. J. Chem. Soc. Faraday Trans. 1990, 86, 425-429.

38. Lohse, U.; Bertram, R.; Jancke, K.; Kurzawaski, I.; Parlitz, B.; Löuffler, E.; Schreier, E. J. Chem. Soc. Faraday Trans. 1995, 91, 1163-1172.

39. Hu, Y.; Navrotsky, A.; Chen, C.-Y.; Davis, M. E. Chem. Mater. 1995, 7, 1816-1823. 


\title{
Supporting information
}

\section{A Facile Synthesis of SAPO-34 Molecular Sieves with Microwave Irradiation in Wide Reaction Conditions}

\author{
Jong Won Jun, Ji Sun Lee, ${ }^{\dagger}$ Huee Young Seok, Jong-San Chang, ${ }^{\dagger}$ Jin-Soo Hwang, ${ }^{\dagger}$ and Sung Hwa Jhung* \\ Department of Chemistry and Green-Nano Materials Research Center, Kyungpook National University, Daegu 702-701, Korea \\ *E-mail: sung@knu.ac.kr \\ ${ }^{\dagger}$ Bio-refinerary Research Center, Korea Research Institute of Chemical Technology, P.O. Box, 107, Yusung, \\ Daejeon 305-600, Korea \\ Received March 3, 2011, Accepted April 30, 2011
}

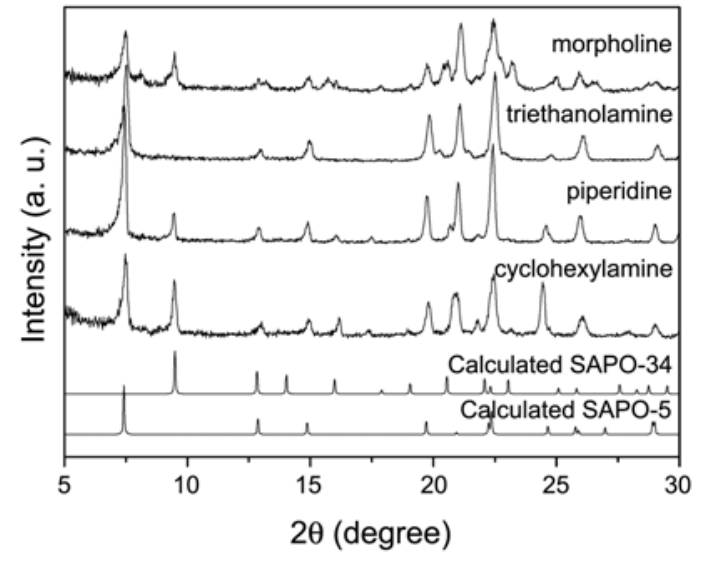

Figure 1. XRD patterns of SAPO molecular sieves that were synthesized for $4 \mathrm{~h}$ at $200{ }^{\circ} \mathrm{C}$ with microwave heating from gels containing various templates. The molar composition of the reaction mixture was $\mathrm{Al}_{2} \mathrm{O}_{3}: 1.0 \mathrm{P}_{2} \mathrm{O}_{5}: 0.30 \mathrm{SiO}_{2}: 2.0$ template : $100 \mathrm{H}_{2} \mathrm{O}$.

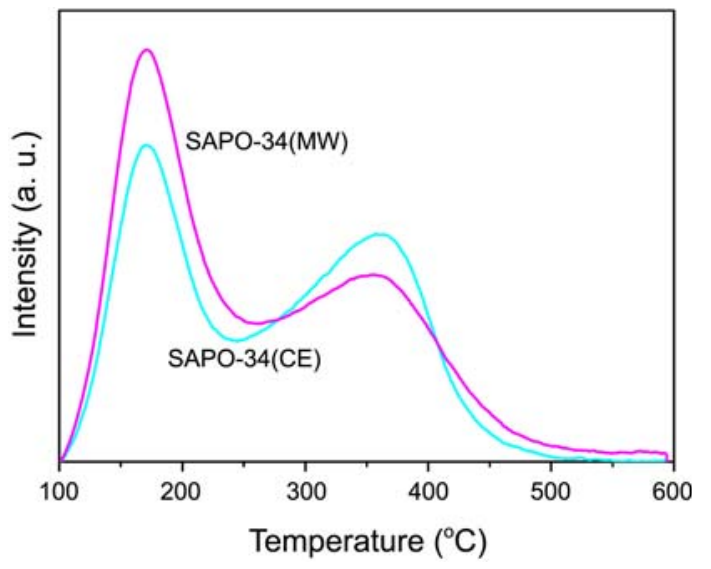

Figure 2. $\mathrm{NH}_{3}$-TPD patterns of SAPO-34 molecular sieves to show the acidic characteristics of the molecular sieves. 